place of psychologists on the Prison Commission and elsewhere.

Psychologists have made three distinctive contributions to the Civil Service Selection Board : first, in the planning of the work of the Board ; secondly, in bringing to its activities a certain quality of expert knowledge in the scientific study of personality; and thirdly, in insisting from the outset on the need for a well-designed follow-up scheme, from which an objective judgment of the value of the board's procedures could be obtained. The last of these contributions, Dr. Anstey believes, is the most important; and the outcome will be a series of reports, the first of which has already appeared.

The main activities of the Research Unit have been job analysis, test construction and follow-up. The follow-up has included an inquiry into the pregress of a hundred entrants to the Administrative Class who, being already employed in the Civil Service, did not go through the Civil Service Selection Board procedure. They had been given instead a more conventional written examination and board interview, though the board interview had been preceded by a private interview. The whole selection procedure had proved satisfactorily valid, when judged two years later by an overall grading of present performance; and the written examination alone had been found to have made a very useful contribution.

Dr. Anstey thinks that the time is ripe for psychologists in the Civil Service Commission to devote more time to discovering how to get the best out of people who have been selected. The incentives problem is of even greater importance in the Civil Service than in private industry. He wants to see more research done on the size and internal organization of the 'working group'; and on what he calls 'internal incentives', which would help individuals to make regular self-assessments of the quality and quantity of their work. $\mathrm{He}$ urged psychologists in the Civil departments to be clear in their own minds about the worthwhileness of their research projects before embarking on them; to make their reports intelligible to non-technical readers; and to aim at striking a satisfactory balance between a high professional standard and practical effectiveness.

Mr. Alec Rodger, reader in psychology at Birkbeck College, University of London, and consulting psychologist to the Admiralty and to the Central Youth Employment Executive, contributed a paper on "Vocational Guidance in Britain", in which he reviewed the past and present work of psychologists in this field and outlined several urgent problems. Conditions for research and development are now more favourable than they have ever been before, partly because the increasing need for the proper use of human resources in industry has directed attention to the advantages of sound guidance. This is shown in the new orientation of the Youth Employ. ment Service and in the work of the Ministry of Labour's Industrial Rehabilitation Units : in both, psychologists have a small but important place.

The most pressing need of all, Mr. Rodger said, is for the clarification of our concepts of occupational success and failure, for without this we shall continue to lack satisfactory criteria whereby to judge the worth of much of our other scientific and technological work. A second need is for better ways of studying the 'requirements' of occupations. Here we have been too long content with the listing of illdefined qualities that have been considered, on the basis of 'hunch', to be important. Empirical investigation is wanted, and it may well be founded provisionally on the notion that the best way to arrive at satisfactory conclusions about the requirements of an occupation is to study people who are acknowledged failures in it, and to compare them with people who are acknowledged successes. Thirdly, there is a need for a better functional classification of occupations. The conventional grouping of them, as concerned with ideas or things or people, is inadequate.

These papers seem to indicate clearly that occupa. tional psychologists in Britain are in considerably better intellectual health than they were in the years immediately before the War. In research and development alike, they are making substantial strides in industry and in the Service and Civil departments. The work of the Service departments is perhaps particularly impressive in its range and quality. The papers read at this discussion are to be published in book form by Messrs Methuen and Co., Ltd.

\section{TREND OF INORGANIC AND PHYSICAL CHEMISTRY SINCE 1850*}

$T$

H.E development of inorganic and physical chemistry during the past hundred years falls into two periods. Until the end of the nineteenth century these two branches of chemistry experienced a steady evolution, while their theoretical foundations, laid at the beginning of modern chemistry, remained unaltered; but about 1900 a revolution set in which changed these very foundations. The difference is as great as the contrast between the quiet security and constant progress of the Victorian age and the upheaval caused in this century by the two World Wars.

One of the greatest achievements during the first period was the discovery of the Periodic Law; it was based on Lavoisier's conception of the chemical element and on the atomic theory founded by Higgins and Dalton. No explanation for the Periodic Law could be given, and fantastic representations without scientific meaning were common; some unfortunate examples of this attitude can still be seen in the science exhibitions of London's Festival of Britain. A real understanding of the Periodic System only became possible after insight into the structure of matter had been gained, mainly as a consequence of the study of radioactive elements and their radiations. Radium was discovered by Pierre and Marie Curie in 1898 , the theory of radioactive disintegrations developed by Rutherford and Soddy in 1902. From this work and from the discovery of isotopy in 1913 by Soddy, J. J. Thomson and Aston, three very important facts emerged which were in contradiction with the doctrines of classical chemistry : (1) elements are not immutable; (2) atoms are complicated structures containing a tremendous store of energy ; (3) atomic weights are not fundamental constants. The recognition of these facts, and great strides made during the same period in experimental and theoretical physics, made it possible for Rutherford and Bohr to crown the old atomic theory by a theory of the atom. According to this theory the chemical character of

* Substance of a paper by Prof. F. A. Paneth, F.R.S., read on August 9 before Section $B$ of the British Association meeting at Edinburgh. 
an atom is determined primarily by the electric charge of the nucleus, not by its weight; atoms of different weight may belong to the same chemical element (isotopes), and atoms of the same weight to different elements (isobars). In this respect modern chemistry is nearer to Higgins's views than to the narrower ones of Dalton.

The advances made in the understanding of the nature of chemical atoms and of their mutual relationship were not only of theoretical interest. The study of the naturally occurring radioactive substances was followed by the artificial disruption of stable atoms, by the production of radioactive isotopes of inactive elements, and-most spectacular of all- by the creation of no less than nine chemical elements which are not to be found on our earth and of which one, plutonium, is the most important source of atomic energy.

The theory of the atom was also able to shed light on the question of chemical forces; in classical chemistry they were considered as something quite different from the forces dealt with in physics, and scarcely capable of further explanation. As atoms are now known to be structures built up of electrically charged particles, the combination of atoms to molecules is to be understood as the consequence of electric forces. All valency bonds are essentially electrostatic in nature, although the mechanism of interaction is different in the two cases of electrovalency and covalency. The exact mathematical treatment is difficult except in the simplest cases, but the possibility of explaining, in principle, all the so-called chemical forces by the laws known to physics can no longer be doubted.

The theory of chemistry is now a part of physics ; but it must not be forgotten that many of the greatest advances in physics have been made on the basis of chemical discoveries. It is safe to predict that for a long time to come the deductive methods of theoretical physics will be supplemented by the inductive approach of the chemist.

\section{IMPROVEMENTS IN CATHODE- RAY TUBE STORAGE: APPLICATION TO A PARALLEL TYPE OF DIGITAL COMPUTER}

\section{By G. H. PERRY}

Telecommunications Research Establishment, Great Malvern

T recent publications ${ }^{1-4}$, Prof. F. C. Williams and Dr. T. Kilburn describe a storage system for use with binary digital computers, using electrostatic charges on the flworescent screen of a cathode-ray tube. In these papers, three possible forms of charge distribution are described, each having two states to represent the binary digits nought and one. These have been named : (a) dot-dash ; $(b)$ defocus-focus ; (c) anticipation. The first of these has been described in detail and has been put into operation in the serial computer in the University of Manchester. In a parallel-operated computer all the digits of a number are used simultaneously, and hence its storage requirements are different from those in a serial machine.
Suppose we have a serial machine using $n$ cathoderay tubes; a number, of $n$ digits, is stored at $n$ points of a single line on a tube which is scanned serially. Adjacent lines store different numbers. If there are also $n$ lines, and one number is required continuously in a computation, then its line will be regenerated $n$ times compared with its neighbour, and this ratio will determine interaction and consequent spacing.

In a parallel machine of the same total capacity of $n^{3}$ digits in $n$ cathode-ray tubes, a single number will be stored at $n$ corresponding points on the $n$ tubes. Again, if this number is required continuously, then each of its points will be regenerated $n^{2}$ times compared with its neighbour. It will be seen how much more serious is the interaction problem than in a serial machine.

When applying cathode-ray tube storage to the parallel computer now being built at the Telecommunications Research Establishment, Malvern, the dot-dash system was found to have several undesirable features. Although these features are all related, they may be considered under three main headings : (1) the interaction between elements of the store was such that the number of digits per cathode-ray tube had to be reduced to a point where it became impracticable for the requirements of a computer ; (2) spurious signals due to imperfections of the fluorescent screen made selection of cathode-ray tubes necessary; with a high rejection-rate this was a costly process, and even then final anode voltages had to be limited to the order of $1 \mathrm{kV}$. in order to minimize these spurious signals; (3) the system was found to be extremely sensitive to variations of the deflexion voltages; even microphony of the valves producing the deflexion voltages could change the stored information.

Using the existing cathode-ray tubes, interaction could be reduced in two main ways: $(a)$ reducing.the net beam current; $(b)$ increasing the final anode voltage of the cathode-ray tube, thus obtaining a finer-focused spot, and using a different portion of the secondary emission characteristics of the fluorescent screen.

A reduction in the net beam-current by about 20 per cent was first obtained by using what may be called a 'double dot' system, where the charge was re-established by a second dot placed a critical distance from the first. The refilling action of this system is slightly more efficient than the dot-dash method. Regarding final anode voltage, experiments showed that an increase reduced the interaction at the expense of signal strength; for example, an increase from 1 to $1.5 \mathrm{kV}$. enabled the separation between digits to be reduced from $1.8 \mathrm{~mm}$. to $0.8 \mathrm{~mm}$. for the same degree of interaction. This represents a fourfold increase in digits per unit area.

For about two years attempts have been made to manufacture cathode-ray tubes with screens which are free from storage imperfection; but so far as is known at the moment, no consistent results have been obtained. The majority of the imperfections were small compared with the cathode-ray tube spot, the diameter of which was $0.5 \mathrm{~mm}$. In an effort to overcome their effect, the cathode-ray tube beam was modulated at $5 \mathrm{Mc}$./sec. at right angles to the line of the double dot. For six cathode-ray tubes tested, it was found that an amplitude of only $0.5 \mathrm{~mm}$. was sufficient to make them work with a final anode voltage of $1.5 \mathrm{kV}$. All these tubes previously had only been satisfactory at $1 \mathrm{kV}$. A single cathode-ray tube store was now constructed 